\title{
Tính toán lựa chọn thành phần cấp phối bê tông cản xạ cốt liệu barit cho hạng mục che chắn nguồn Cobalt 60
}

\author{
Dương Ngọc Đức ${ }^{1 *}$, Vũ Hải Quang ${ }^{2}$ \\ ${ }^{1}$ Trung tâm Đánh giá không phá hủy - Viện Năng lượng nguyên tử Việt Nam \\ ${ }^{2}$ Viện Vật liệu xây dựng
}

TỪ KHOÁ

Bê tông siêu nặng

Bê tông cản xạ

Bê tông barit

Cấp phối bê tông

Che chắn bức xạ

\begin{abstract}
TÓM TẮT
Vật liệu bê tông được sử dụng phổ biến trong các công trình xây dựng, ngoài ra còn được ứng dụng làm vật liệu che chắn bức xạ trong các cơ sở tiến hành công việc chiếu chụp bức xạ. Trong nghiên cứu này chúng tôi tiến hành tính toán lực chọn thành phần cấp phối bê tông mác M30 cốt liệu barit có khối lượng riêng từ $2,4 \mathrm{~g} / \mathrm{cm}^{3}$ đến $3,2 \mathrm{~g} / \mathrm{cm}^{3}$, dùng phương pháp ghi đo bức xạ trực tiếp xác định hệ số cản xạ của các mẫu bê tông đó bằng cách đưa vào trường chiếu nguồn Cobalt 60 . Việc tính toán lựa chọn thành phần cấp phối bê tông với khối lượng riêng lớn khác nhau giúp giảm khối lượng bê tông khi thi công, tăng diện tích sử dụng vừa đảm bảo tính chịu lực của kết cấu vừa đảm bảo che chắn an toàn bức xạ cho hạng mục công trình.
\end{abstract}

\section{ABSTRACT}

Concrete material is commonly used in construction works, in addition to being used as a radiation shielding material in radiation imaging facilities. In this study, we design a barite-aggregated concrete mix with the density from $2,4 \mathrm{~g} / \mathrm{cm}^{3}$ to $3,2 \mathrm{~g} / \mathrm{cm}^{3}$, this concrete's radioactive resistance value is equal to irradiation with a cobalt 60 gamma source on the sample. The design of concrete mix with different densities helps to reduce material thickness, increase the usable area while ensuring the bearing capacity of the structure and ensuring radiation safety for construction items.

\section{Giới thiệu}

Hiện nay trên thế giới, ứng dụng năng lượng nguyên tử trong các ngành kinh tế đang dần chiếm tỷ trọng cao. Nhu cầu ứng dụng và sử dụng các nguồn bức xạ đang ngày càng phổ biến.

Các công trình xây dựng như phòng xạ trị, phòng chụp ảnh công nghiệp hay các công trình xây dựng như công trình nhà máy điện hạt nhân, lò phản ứng, các hạng mục trong công trình xây dựng đó đều được phân loại và phân cấp theo mức độ bảo đảm về mặt an toàn bức xạ hạt nhân. Tùy theo mức độ yêu cầu đảm bảo an toàn bức xạ, các hạng mục đó sẽ có những yêu cầu về vật liệu xây dựng sử dụng. Việc sản xuất quy mô lớn các chất phóng xạ và vật liệu phóng xạ, xây dựng và sử dụng lò phản ứng hạt nhân, máy gia tốc hạt, chụp $\mathrm{X}$ quang công nghiệp, liệu pháp tia gamma, đòi hỏi phải có vật liệu che chắn để bảo vệ nhân viên vận hành chống lại các mối nguy sinh học của bức xạ như vậy.

Bê tông được biết đến là một loại vật liệu truyền thống và được sử dụng rộng rãi trong nhiều lĩnh vực như xây dựng, giao thông, công nghiệp, thủy lợi. Bê tông được mệnh danh là "Vật liệu của thế kỷ XX" thể hiện rõ vai trò của nó trong sự phát triển kinh tế của thế giới.

Sự ra đời của ngành năng lượng hạt nhân cho thấy nhu cầu đáng kể về công nghệ bê tông hướng tới mục đích che chắn chống phóng xạ. Bê tông là một vật liệu che chắn tuyệt vời sở hữu các đặc tính cần thiết cho cả sự suy giảm tia neutron và tia gamma, có tính chất cơ học thỏa đáng và có chi phí chế tạo thi công bảo trì tương đối thấp. Ngoài ra sự dễ dàng của việc chế tạo thi công làm cho bê tông trở thành một vật liệu đặc biệt phù hợp để che chắn bức xạ.

Công nghệ thiết kế chế tạo bê tông có sự thay đổi mạnh nhằm tăng hiệu quả chống cản xạ của vật liệu này. Một trong các hướng đó là thay thế các cốt liệu truyền thống bằng các nguồn cốt liệu tự nhiên khác hoặc cốt liệu nhân tạo nhằm tăng đặc tính cản xạ của bê tông đối với các nguồn bức xạ gamma và notron.

\subsection{Tình hình nghiên cứu bê tông cản xạ trên thế giới}

Nghiên cứu của Kilincarslan và cộng sự [2] đã chỉ ra mối liên quan giữa tỷ lệ barit đối với tính chất cơ lý của bê tông, giữa tỷ trọng bê tông, cường độ sóng siêu âm, độ cứng, tỷ lệ nước/xi măng và tỷ lệ barit có mối quan hệ với nhau.

Nghiên cứu của Izaz Ahmad và cộng sự [3] về độ đặc chắc của bê tông sử dụng Barit làm cốt liệu mịn và ảnh hưởng của nó đến các đặc tính cơ học và che chắn bức xạ của bê tông chỉ ra mối quan hệ 
giữa hàm lượng barit và khả năng cản xạ của bê tông sử dụng cốt liệu mịn barit, xác định mối quan hệ tỷ lệ thuận giữa hệ số suy giảm tuyến tính và mật độ, từ đó cũng đưa đến kết luận có thể sử dụng barit thay cát mà không ảnh hưởng sâu sắc đến các tính chất cơ học của bê tông.

Nghiên cứu của K.A. Mahmoud và cộng sự [4] đánh giá sự ảnh hưởng của kích thước cốt liệu đá bazan và tốc độ gia tải tới cường độ nén và khả năng cản xạ của bê tông đã đưa ra nhận xét về mối quan hệ giữa kích cỡ hạt với hệ số suy giảm khối của bê tông cốt liệu bazan.

Nghiên cứu của I. Akkurt và cộng sự [5] so sánh giữa khả năng suy giảm của bức xạ gamma đối với chì và bê tông barit với các tỷ lệ khác nhau dựa trên giá trị giảm nửa HVL và giá trị giảm mười TVL cũng đưa ra kết luận về khả năng suy giảm bức xạ gamma của bê tông barit là được cải thiện đáng kể.

Nghiên cứu của V. Fugaru và cộng sự [6] về mối quan hệ giữa hệ số suy giảm tuyến tính của bê tông thường, bê tông cốt liệu barit và bê tông cốt liệu witherite với các nguồn gamma Co-60: $1,25 \mathrm{MeV}$; Cs-137: 0,662 MeV ; Ir-192: 0,37 MeV chỉ ra mối quan hệ tuyến tính giữa hệ số suy giảm tuyến tính đối với từng loại cốt liệu cũng như mối quan hệ tuyến tính giữa hệ số suy giảm tuyến tính đối với năng lượng bức xạ gamma.

Các nghiên cứu trên thế giới nêu trên cho thấy sử dụng đá barite làm cốt liệu thay thế cốt liệu truyền thống để chế tạo bê tông nhưng chưa chỉ rõ ứng dụng trong việc thiết kế xây dựng các công trình xây dựng có hạng mục yêu cầu tính cản xạ có thể áp dụng giảm diện tích xây dựng ở chỉ tiêu kỹ thuật nào.

\subsection{Tình hình nghiên cứu bê tông cản xạ ở Việt Nam}

Tại Việt Nam, nhu cầu về sử dụng các máy xạ trị Cobalt 60 và máy gia tốc dùng trong xạ trị y tế đang tăng lên, các bệnh viện cấp tỉnh và trung ương đều đã và đang được trang bị các hệ thiết bị này tới thời điểm hiện nay là hơn 50 máy, và sẽ còn tăng nữa theo chủ trương của chính phủ.

Trong công nghiệp, phương pháp kiểm tra không phá hủy bằng kỹ thuật chụp ảnh phóng xạ cũng có nhu cầu sử dụng nguồn năng lượng cao hay hoạt độ cao (máy gia tốc, nguồn Cobalt 60) do các đối tượng sản phẩm có chủng loại kích thước phong phú hơn, đòi hỏi kỹ thuật và cấu hình kiểm tra cao hơn mới đáp ứng được yêu cầu kỹ thuật.

Các công trình xây dựng có hạng mục yêu cầu đảm bảo an toàn bức xạ như phòng xạ trị máy gia tốc hay phòng chụp ảnh bức xạ trong công nghiệp đã và đang thi công đưa vào sử dụng dùng vật liệu bê tông thông thường là phổ biến. Vật liệu này hiện nay tại Việt Nam chỉ được đánh giá bằng các chỉ tiêu cơ lý hóa phục vụ cho các công trình xây dựng thông thường.

Ở Việt Nam, nhóm nghiên cứu của tác giả Vũ Mạnh Hùng [14] đã nghiên cứu chế tạo vữa bê tông barit đạt chỉ tiêu cơ lý của vữa xây dựng và xác định giá trị tương đương chì của vật liệu, ứng dụng trong các cơ sở $\mathrm{X}$ quang.

Trường Đại học Xây dựng Hà Nội cũng nghiên cứu và đưa ra cấp phối bê tông rất nặng phù hợp để chống phóng xạ, khảo sát mẫu bê tông với thành phần là nguồn cốt liệu đá barit Tuyên Quang và xi măng Bút Sơn. Nghiên cứu của tác giả Trần Ngọc Tính [15] về ảnh hưởng phụ gia siêu dẻo đến cường độ và cấu trúc bê tông cản xạ chỉ ra tác dụng của phụ gia siêu dẻo đến tuổi bê tông, ảnh hưởng của cốt liệu barit Tuyên Quang và barit Nghệ An và quặng sắt tới cấu trúc của bên tông cản xạ.

Nghiên cứu của tác giả Nguyễn Mạnh Kiểm và cộng sự [17] về tiềm năng nguồn nguyên liệu trong nước phục vụ chế tạo bê tông cản xạ phục vụ cho xây dựng các nhà máy điện nguyên tử cũng đưa ra kết quả nghiên cứu đối với bê tông cốt liệu barit, chưa xác định chỉ tiêu cản xạ cụ thể.

Vấn đề nghiên cứu bê tông chống phóng xạ, bê tông siêu nặng ở Việt Nam chưa đưa ra được chỉ tiêu cản xạ cụ thể trong đặc tính kỹ thuật của vật liệu bê tông, mới chỉ dẫn dắt đến mối liên hệ tỷ lệ thuận giữa khối lượng thể tích và khả năng suy giảm bức xạ của vật liệu này. Vấn đề về ứng dụng sử dụng của vật liệu trong các công trình có những ưu nhược điểm gì cũng chưa được đề cập chi tiết cụ thể.

Từ các nghiên cứu trên, đề tài "Nghiên cứu lựa chọn thành phần bê tông cốt liệu barit cản xạ cho hạng mục che chắn nguồn Co60" được thực hiện với mục tiêu nghiên cứu tìm hiểu và lựa chọn vật liệu phù hợp, đáp ứng yêu cầu tối ưu hóa diện tích xây dựng, tăng hệ số sử dụng và diện tích sử dụng với các hạng mục công trình xây dựng có yêu cầu chỉ tiêu cản xạ.

Mục tiêu của đề tài là lựa chọn được thành phần cấp phối bê tông đặc biệt có khả năng cản xạ tốt hơn bê tông thông thường, thể hiện bằng chỉ tiêu cản xạ cụ thể, nhằm giảm khối lượng thi công, tiết kiệm chi phí xây dựng, tăng hiệu quả khai thác sử dụng mặt bằng diện tích công trình xây dựng.

Đối tượng nghiên cứu: Vật liệu bê tông sử dụng trong công trình đó phổ biến được chia làm hai loại: bê tông thông thường, không yêu cầu tính cản xạ, và bê tông đặc biệt, ngoài yêu cầu kỹ thuật chung trong xây dựng, có thêm chỉ tiêu che chắn cản xạ. Các nghiên cứu về bê tông nặng với mục đích che chắn cản xạ với các thành phần cốt liệu khác nhau đều đưa ra những chỉ tiêu quan trọng là cường độ nén, độ sụt và khả năng che chắn cản xạ của bê tông với các nguồn bức xạ khác nhau.

Phương pháp tiếp cận: Thiết kế thành phần bê tông thông thường, thay đổi cốt liệu cát, đá bằng cốt liệu quặng barit, xác định các chỉ tiêu cường độ nén, độ sụt, khối lượng thể tích và giá trị cản xạ, từ đó xác định thành phần cấp phối bê tông với giá trị cản xạ tối ưu.

Các kết quả chính của đề tài : Xác định các cấp phối bê tông cản xạ có khả năng che chắn cản xạ tốt hơn bê tông thông thường đáp ứng yêu cầu của bê tông mác M30, xác định giá trị cản xạ của từng cấp phối tương ứng và làm rõ tính ứng dụng giảm diện tích và khối lượng xây dựng cho các hạng mục công trình có yêu cầu che chắn cản xạ.

2. Tính toán lựa chọn thành phần và chế tạo thực nghiệm bê tông cản xạ

2.1. Nguyên vật liệu sử dụng trong nghiên cứu 


\subsubsection{Xi măng}

Xi măng Nghi Sơn PCB40 được sử dụng làm chất kết dính trong nghiên cứu này. Các chỉ tiêu cơ lý của xi măng PCB 40 Nghi Sơn thỏa mãn các yêu cầu của TCVN 6260:2011.

\subsubsection{Cát vàng sông $L \hat{o}$}

Cốt liệu nhỏ sử dụng trong nghiên cứu được sàng loại bỏ hạt lớn hơn $2,5 \mathrm{~mm}$ từ cát vàng Sông Lô. Các chỉ tiêu cơ lý của cát thỏa mãn yêu cầu cốt liệu nhỏ sử dụng của TCVN 7572: 2006.

\subsection{3. Đá dăm}

Đá dăm sử dụng trong nghiên cứu là đá dăm Hà Nam kích thước $5 \mathrm{~mm}$ đến $20 \mathrm{~mm}$. Các chỉ tiêu cơ lý của đá dăm thỏa mãn yêu cầu cốt liệu lớn sử dụng trong bê tông theo yêu cầu kĩ thuật TCVN 7572: 2006.

\subsubsection{Cốt liệu quặng barite}

Trong nghiên cứu sử dụng quặng barite tại mỏ đá Bắc Giang làm cốt liệu mịn và cốt liệu thô.

Các cốt liệu quặng barite trước khi đưa vào sử dụng được gia công cỡ hạt theo yêu cầu, thành phần hạt phù hợp với vật liệu chế tạo bê tông, chỉ tiêu này đều nằm trong phạm vi cho phép theo TCVN 7570-2006.

\subsubsection{Nước}

Nước được sử dụng trong nghiên cứu thỏa mãn yêu cầu kỹ thuật đối với nước trộn trong bê tông được quy định trong TCVN 4506:1987.

\subsubsection{Phụ gia hóa học}

Phụ gia hóa học sử dụng trong nghiên cứu có tên thương mại Sika 300-2M của hãng Sika gốc polycacboxylat. Tính chất của phụ gia hóa học sử dụng trong nghiên cứu thỏa mãn yêu cầu của TCVN 8826:2011.

\subsection{Phương pháp tiến hành}

Tính toán cấp phối bê tông theo "Chỉ dẫn kỹ thuật - Chọn thành phần bê tông các loại” tuân thủ hướng dẫn của Bộ Xây dựng.

\subsubsection{Các cấp phối cần tính toán}

Các cấp phối cần tính toán bao gồm cấp phối bê tông sử dụng cốt liệu tự nhiên (làm đối chứng) và các cấp phối sử dụng quặng barite thay thế cát tự nhiên và đá dăm. Trong phạm vi đề tài sử dụng cấp phối đối với mác bê tông $300 \mathrm{daN} / \mathrm{cm}^{2}$., tổng số có 4 cấp phối nghiên cứu trong đó có 1 cấp phối đối chứng.

\subsubsection{Xác định thành phần cấp phối}

Áp dụng phương pháp tính toán thiết kế chế tạo cấp phối bê tông theo "CHỈ DẪN KỸ THUẬT CHỌN THÀNH PHẦN BÊ TÔNG CÁC LOẠI", ta xác định được cấp phối sử dụng trong nghiên cứu này (Bảng 1).

\section{Tiến hành xác định thực nghiệm các đặc tính của bê tông cản xạ 3.1. Xác định độ sụt}

Phương pháp tiến hành: Xác định độ sụt của hỗn hợp bê tông theo tiêu chuẩn TCVN 3106:1993.

Kết quả: Kết quả thí nghiệm độ sụt của hỗn hợp bê tông tươi được thể hiện qua Bảng 2 và Hình 1.

\subsection{Xác định khối lượng thể tích}

Phương pháp tiến hành: Xác định khối lượng thể tích của hỗn hợp bê tông theo tiêu chuẩn TCVN 3108:1993.

Kết quả khối lượng thể tích thể hiện trong Bảng 3 và Hình 2 .

\subsection{Xác định cường độ nén bê tông}

Phương pháp tiến hành: Xác định cường độ nén bê tông theo TCVN 3118:1993. Kết quả thử nghiệm cường độ nén thể hiện qua Bảng 4 và Hình 3.

\subsection{Xác định giá trị cản xạ của bê tông}

\subsubsection{Cơ sở lý thuyết xác định giá trị cản xạ của bê tông}

Tia $\mathrm{X}$ và tia gamma có cùng bản chất sóng điện từ, đó là các photon năng lượng cao. Do sự tương tác của các tia này với vật chất có tính chất chung nên để đơn giản ta gọi là tương tác của tia gamma với vật chất.

Tương tác của bức xạ tia $\mathrm{X}$ và tia gamma với vật chất : Sự suy giảm của tia gamma, tia $\mathrm{X}$ khi đi qua môi trường khác với sự suy giảm của các hạt tích điện. Khi cho một chùm tia gamma hoặc tia $\mathrm{X}$ hẹp đi qua bản vật liệu và đo cường độ chùm tia sau bản vật liệu đã được chuẩn trực, sự phụ thuộc của cường độ chùm tia theo bề dày vật liệu sẽ có dạng hàm e mũ. Nếu sử dụng đồ thị bán logarit, đồ thị có dạng đường thẳng giảm khi bề dày tăng.

Xét một chùm tia gamma hẹp đơn năng có cường độ ban đầu $\mathrm{I}_{0}$. Sự thay đổi cường độ khi đi qua một lớp vật liệu mỏng $\mathrm{dx}$ bằng:

$$
d I=-\mu I d x
$$

trong đó $\mu$ là hệ số suy giảm tuyến tính.

Từ (1) có thể viết:

$$
\frac{\mathrm{dI}}{\mathrm{I}}=-\mu \mathrm{dx}
$$

Tích phân phương trình này từ 0 đến $\mathrm{x}$ ta được:

$$
\mathrm{I}=\mathrm{I}_{0} \cdot \mathrm{e}^{-\mu x}=\mathrm{I}_{0} \cdot \mathrm{e}^{-\mu m d}
$$

trong đó: 
$x$ là bề dày lớp hấp thụ;

$d$ là bề dày khối của lớp hấp thụ;

$\mathrm{I}_{0}$ là cường độ ban đầu của nguồn bức xạ gamma;

I là cường độ của nguồn bức xạ gamma sau khi đi qua lớp hấp thụ có bề dày $x$ hay bề dày khối $d$;

$\mu$ là hệ số suy giảm tuyến tính, phụ thuộc vào loại vật liệu che chắn được dùng và vào năng lượng của tia gamma tới, đơn vị đo là $\mathrm{cm}^{-1}$.

$\mu_{m}$ là hệ số suy giảm khối.

Sự làm yếu tia gamma và tia $\mathrm{X}$ gây bởi hai quá trình: hấp thụ và tán xạ. Trong quá trình hấp thụ, các tia gamma và tia $\mathrm{X}$ biến mất sau khi truyền toàn bộ năng lượng cho các hạt vật chất, làm cho các hạt này di chuyển trong môi trường. Trong quá trình tán xạ, tia gamma và tia $\mathrm{X}$ tương tác làm xuất hiện các hạt chạy nhanh hơn, nhưng các hạt này chỉ thu một phần nhỏ năng lượng của chùm tia, các tia gamma và tia $\mathrm{X}$ sau tán xạ bị giảm năng lượng và thay đổi phương chuyển động, tách khỏi thành phần của chùm tia tới. Người ta phân ba loại hiệu ứng cơ bản trong quá trình làm chậm tia gamma và tia $\mathrm{X}$ là: Hiệu ứng quang điện, hiệu ứng Compton và hiệu ứng tạo cặp (Positron - electron).

Bảng 1. Cấp phối nghiên cứu sử dụng quặng barite thay thế cốt liệu tự nhiên.

\begin{tabular}{|c|c|c|c|c|c|c|c|c|c|c|}
\hline STT & $\begin{array}{c}\text { Mẫu cấp } \\
\text { phối }\end{array}$ & $\begin{array}{l}\text { Xi măng } \\
(\mathrm{kg})\end{array}$ & $\begin{array}{l}\text { Cát } \\
\text { (kg) }\end{array}$ & $\begin{array}{c}\text { Đá } \\
(\mathrm{kg})\end{array}$ & $\begin{array}{c}\text { Cát barite } \\
(\mathrm{kg})\end{array}$ & $\begin{array}{c}\text { Đá barite } \\
(\mathrm{kg})\end{array}$ & $\begin{array}{l}\text { Nước } \\
\text { (Lít) }\end{array}$ & $\begin{array}{c}\text { Phụ gia } \\
\text { (Lít) }\end{array}$ & Độ sụt (cm) & $\begin{array}{c}\text { Tỷ lệ N/X } \\
(\%)\end{array}$ \\
\hline 1 & CP1 & 385 & & 1145 & 985 & & 215 & 3,85 & $10 \pm 2$ & 0,56 \\
\hline 2 & CP2 & 385 & & & 1393 & 1292 & 230 & 3,85 & $10 \pm 2$ & 0,60 \\
\hline 3 & CP3 & 385 & 855 & & & 1365 & 210 & 3,85 & $10 \pm 2$ & 0,55 \\
\hline 4 & CP4 & 385 & 785 & 1015 & & & 200 & 3,85 & $10 \pm 2$ & 0,52 \\
\hline
\end{tabular}

Bảng 2. Kết quả thí nghiệm độ sụt của hỗn hợp bê tông sử dụng quặng barite.

\begin{tabular}{|c|c|c|c|}
\hline STT & Mẫu cấp phối & Độ sụt sau khi trộn, cm & Độ sụt sau 30 phút, cm \\
\hline 1 & CP1 & 9 & 8 \\
\hline 2 & CP2 & 8 & 7 \\
\hline 3 & CP3 & 8 & 8 \\
\hline 4 & CP4 & 11,5 & 10 \\
\hline
\end{tabular}

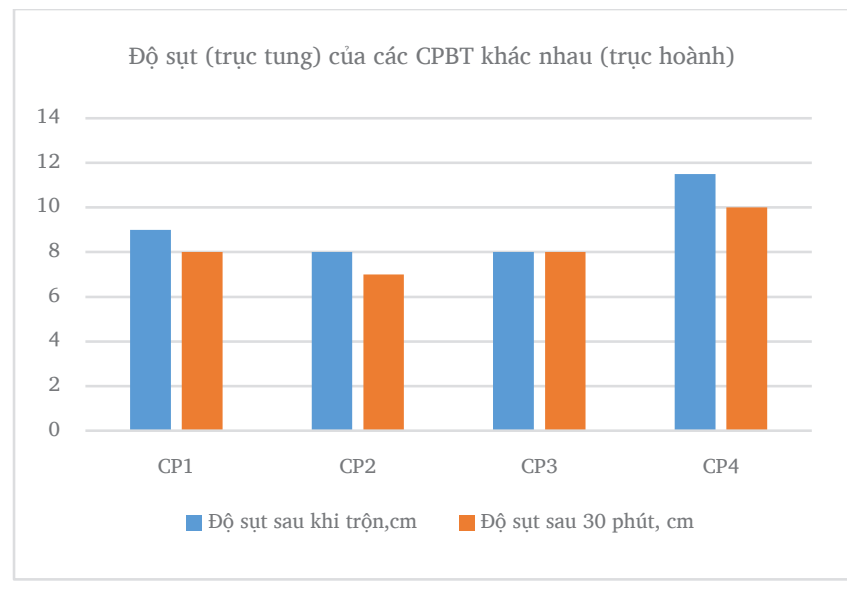

Hình 1. Độ sụt của hỗn hợp bê tông sau khi trộn và sau 30 phút.

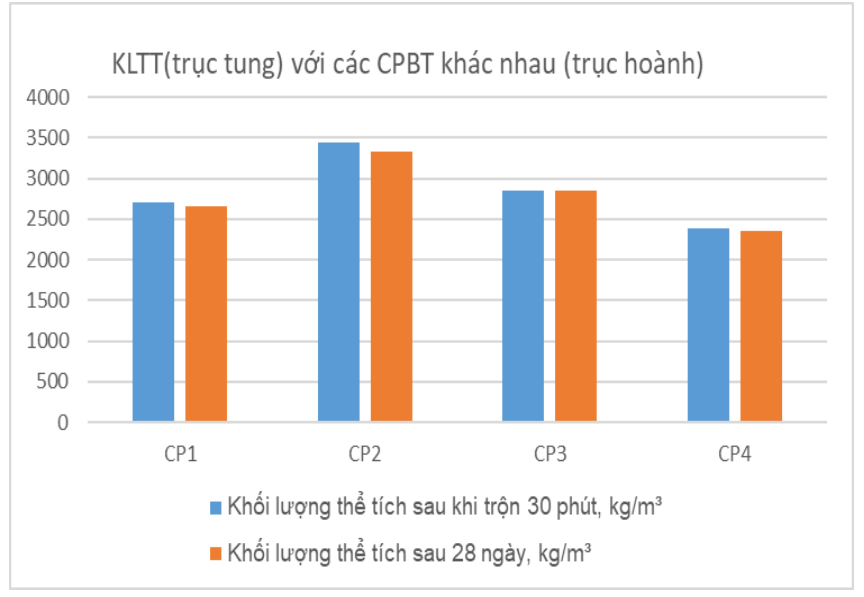

Hình 2. Khối lượng thể tích của các hỗn hợp bê tông sau khi trộn và sau 28 ngày.

Bảng 3. Khối lượng thể tích của hỗn hợp bê tông sau khi trộn 30 phút và sau 28 ngày.

\begin{tabular}{|c|c|c|c|}
\hline STT & Tên mẫu & $\begin{array}{c}\text { Khối lượng thể tích sau khi trộn } 30 \\
\text { phút, } \mathrm{kg} / \mathrm{m}^{3}\end{array}$ & $\begin{array}{c}\text { Khối lượng thể tích sau } 28 \text { ngày, } \\
\mathrm{kg} / \mathrm{m}^{3}\end{array}$ \\
\hline 1 & CP1 & 2700 & 2660 \\
\hline 2 & CP2 & 3448 & 3328 \\
\hline 3 & CP3 & 2848 & 2844 \\
\hline
\end{tabular}




\begin{tabular}{|l|l|l|l|}
\hline 4 & CP4 & 2388 & 2348 \\
\hline
\end{tabular}

Bảng 4. Cường độ nén mẫu bê tông thí nghiệm.

\begin{tabular}{|c|c|c|}
\hline STT & Tên mẫu & Cường độ nén 28 ngày (MPa) \\
\hline 1 & CP1 & 34,4 \\
\hline 2 & CP2 & 30,4 \\
\hline 3 & CP3 & 36,9 \\
\hline 4 & CP4 & 38,9 \\
\hline
\end{tabular}

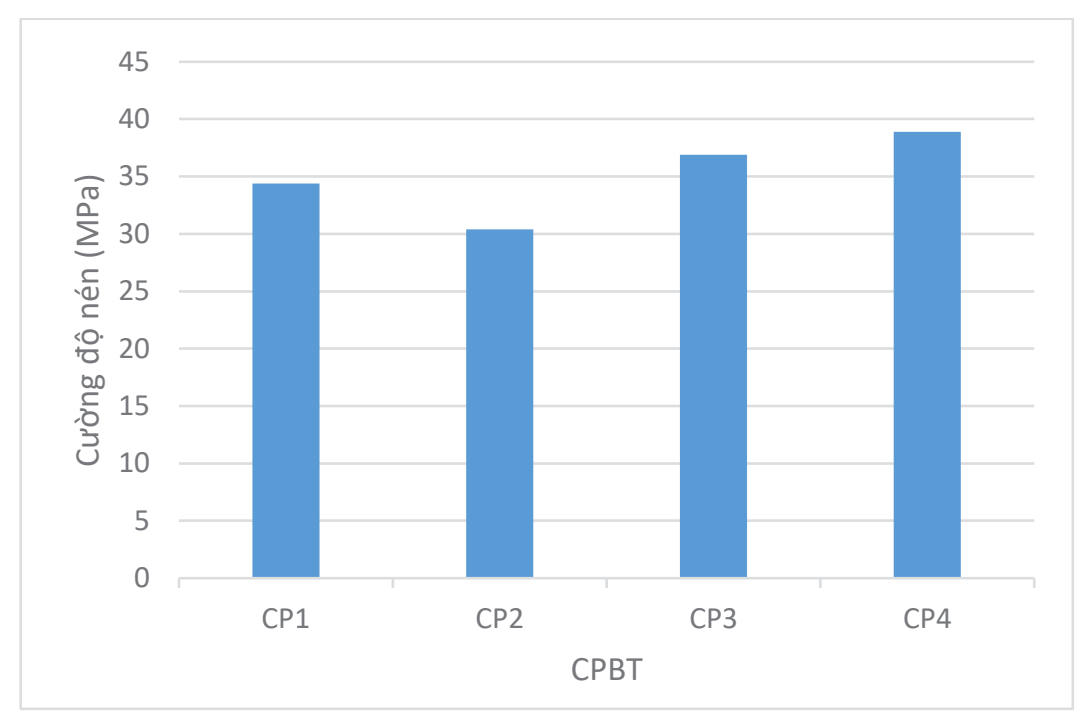

Hình 3. Cường độ nén mẫu thí nghiệm ở thời điểm 28 ngày.

\subsubsection{Nguyên tắc tính toán che chắn tia gamma}

Sự suy giảm của tia $\mathrm{X}$ và tia gamma khi đi qua vật chất: Tia $\mathrm{X}$ và tia gamma bị suy giảm theo hàm mũ khi chúng đi qua vật liệu. Sự suy giảm này có thể được biểu diễn bằng phương trình (3).

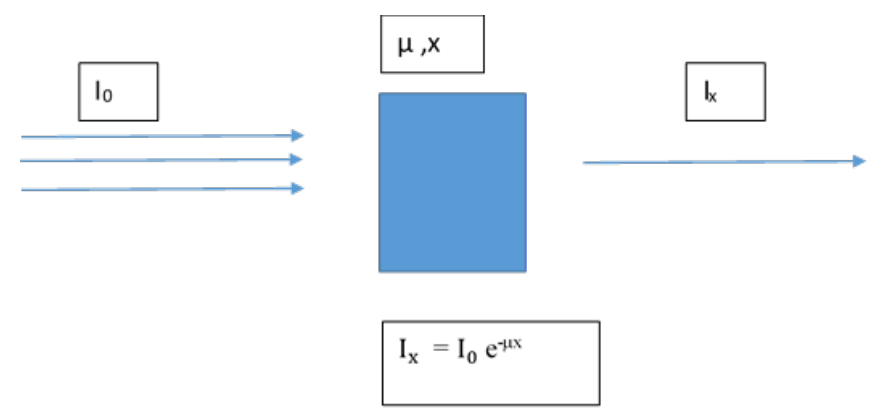

Hình 4. Sự suy giảm cường độ bức xạ tia $\mathrm{X}$ và tia gamma khi đi qua vật liệu.

Hệ số suy giảm tuyến tính phụ thuộc vào loại vật liệu che chắn được dùng và vào năng lượng của tia gamma tới. Nó thường được đưa ra trong đơn vị $\mathrm{cm}^{-1}$.

- Lớp làm yếu một nửa HVL, cũng được gọi là bề dày làm yếu một nửa đối với một vật liệu che chắn nhất định, là bề dày lớp che chắn của vật liệu đó cần thiết để giảm cường độ bức xạ tới giá trị một nửa của giá trị ban đầu :

$$
\mathrm{I}_{\mathrm{x}}=\mathrm{I}_{0} / 2^{\mathrm{n}}
$$

trong đó $n=$ bề dày che chắn bằng số $H V L$

$\mathrm{I}_{\mathrm{x}}=$ Cường độ bức xạ tia gamma sau khi qua lớp che chắn có bề dày $x$

$\mathrm{I}_{0}=$ Cường độ bức xạ tia gamma khi không che chắn

+ Bề dày thực tế $(\mathrm{x})$ của lớp che chắn sẽ là : $x=n \cdot H V L$

+ Mối quan hệ giữa hệ số suy giảm tuyến tính $\mu$ và lớp làm yếu một nửa (HVL):

$\mathrm{HVL}=\operatorname{Ln} 2 / \mu$

- Lớp làm yếu bậc mười (TVL) được định nghĩa là bề dày vật liệu che chắn cần thiết để giảm cường độ bức xạ đến một phần mười giá trị ban đầu :

$$
\mathrm{I}_{\mathrm{x}}=\mathrm{I}_{0} / 10^{\mathrm{n}}
$$

trong đó $\mathrm{n}=$ bề dày lớp che chắn dưới dạng số các lớp TVL

$\mathrm{I}_{\mathrm{x}}=$ Cường độ bức xạ tia gamma sau khi qua lớp che chắn có bề dày $\mathrm{x}$

$\mathrm{I}_{0}=$ Cường độ bức xạ tia gamma không che chắn

+ Bề dày thực tế $(\mathrm{x})$ của lớp che chắn sẽ là : $\quad x=n \cdot T V L$

+ Mối liên hệ giữa hệ số suy giảm tuyến tính $\mu$ và lớp làm yếu bậc mười TVL sẽ là :

$$
T V L=\operatorname{Ln} 10 / \mu
$$


Bê tông là một trong các loại vật liệu được sử dụng vào mục đích che chắn bức xạ gamma. Khả năng che chắn bức xạ gamma của bê tông thông thường (khối lượng thể tích $\rho=2,35 \mathrm{~g} / \mathrm{cm}^{3}$ ) thể hiện ở Bảng 5 . Bảng 5. Giá trị HVL và TVL đối với một số nguồn tia $X$ và gamma.

\begin{tabular}{|c|c|c|c|c|c|}
\hline \multirow{2}{*}{ Nguồn } & $\begin{array}{c}\text { Năng lượng } \\
(\mathrm{MeV})\end{array}$ & \multicolumn{2}{|c|}{ HVL $(\mathrm{cm})$} & \multicolumn{2}{c|}{ TVL (cm) } \\
\cline { 3 - 6 } & & Bê tông & Chì & Bê tông & Chì \\
\hline${ }^{226} \mathrm{Ra}$ & 0,047 đến 2,4 & 6,9 & 1,66 & 23,4 & 5,5 \\
\hline${ }^{60} \mathrm{Co}$ & 1,17 và 1,33 & 6,2 & 1,2 & 20,6 & 4 \\
\hline${ }^{137} \mathrm{Cs}$ & 0,66 & 4,8 & 0,65 & 15,7 & 2,1 \\
\hline${ }^{192} \mathrm{Ir}$ & 0,13 đến 1,06 & 4,3 & 0,6 & 14,7 & 2 \\
\hline Tia X & $50 \mathrm{kVp}$ & & 0,43 & & 1,5 \\
\hline Tia X & $100 \mathrm{kVp}$ & & 1,6 & & 5,3 \\
\hline \multicolumn{7}{|c|}{$(\mathrm{NCRP}$ Report No. 49 1976) } \\
\hline
\end{tabular}

Theo truyền thống, khi dùng vật liệu che chắn đối với nguồn bức xạ gamma đã xác định mức năng lượng, để giảm cường độ bức xạ khi qua vật liệu che chắn, người ta lựa chọn tăng chiều dày vật liệu che chắn $\mathrm{x}$.

\section{Nguyên tắc tính toán che chắn tia gamma trên cơ sở sử dụng vật liệu có mất độ cao}

Sự suy giảm của tia gamma khi đi qua vật liệu che chắn phụ thuộc vào hai yếu tố, bề dày che chắn $\mathrm{x}$ và hệ số suy giảm tuyến tính của vật liệu.

Với vật liệu hỗn hợp hệ số suy giảm theo mật độ vật liệu được tính theo công thức: hệ số suy giảm khối lượng $\mu_{\mathrm{k}}=\frac{\mu}{\rho}$ với $\rho$ là mật độ vật liệu.

Hệ số suy giảm khối của một hợp chất hay hỗn hợp của các nguyên tố có thể được tính theo:

$$
\left(\frac{\mu}{\rho}\right)=\sum_{i} w_{i}\left(\frac{\mu}{\rho}\right)_{i}
$$

ở đó hệ số $w_{i}$ thể hiện tỷ phần khối lượng của nguyên tố $i$ trong hợp chất hay hỗn hợp.

Trên cơ sở thay đổi thành phần cốt liệu bê tông, ta có thể lựa chọn cốt liệu có mật độ $\rho$ lớn để tăng mật độ bê tông nhằm tăng khả năng cản xạ.

\subsubsection{Xác định thực nghiệm}

Cấu hình ghi đo thực nghiệm xác định giá trị giảm nửa HVL và giá trị giảm mười TVL đối với nguồn bức xạ Cobalt 60 của mẫu cấp phối bê tông thí nghiệm được bố trí như Hình 5 , các thông số cơ bản về cấu hình ghi đo và che chắn thể hiện trong Bảng 6 .

Các bước tiến hành:

- Xác định số đếm ban đầu $\mathrm{I}_{0}$ :

- Xác định số đếm I, tốc độ đếm $r$ của từng tổ mẫu tương ứng các cấp phối CP1, CP2, CP3, CP4.
- Xác định giá trị cản xạ HVL theo công thức (5) và TVL theo công thức (6):

Kết quả thí nghiệm và tính toán thể hiện qua Bảng 7.

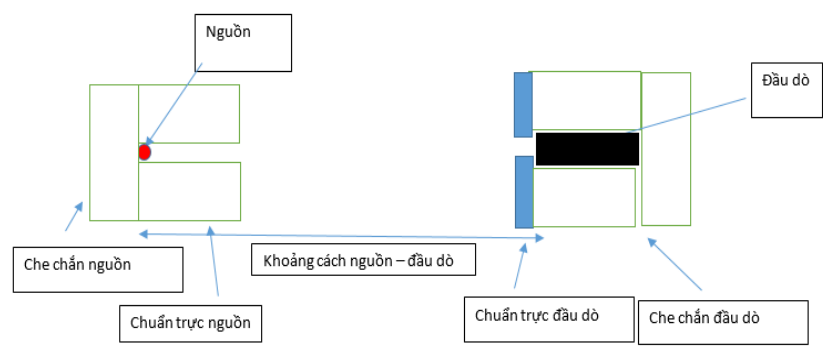

Hình 5. Bố trí thí nghiệm ghi đo bức xạ gamma.

Bảng 6. Cấu hình ghi đo và che chắn.

\begin{tabular}{|l|l|}
\hline Hoạt độ nguồn tại thời điểm đo: & $31,2 \mathrm{Ci}$ \\
\hline Suất liều phóng xạ tại $1 \mathrm{~m}:$ & $406 \mathrm{mSv} / \mathrm{h}$ \\
\hline Độ dày chì tới suất liều $0,2 \mu \mathrm{Sv}$ tại $1 \mathrm{~m}:$ & $25,25 \mathrm{~cm}$ \\
\hline Đường kính lỗ chuẩn trực: & $30 \mathrm{~mm}$ \\
\hline Bề dày chì che chắn chuẩn trực nguồn: & $300 \mathrm{~mm}$ \\
\hline Bề dày chì che chắn chuẩn trực đầu dò: & $50 \mathrm{~mm}$ \\
\hline Bề dày chì che chắn xung quanh đầu dò: & $100 \mathrm{~mm}$ \\
\hline Khoảng cách nguồn - đầu dò: & $3000 \mathrm{~mm}$ \\
\hline
\end{tabular}

Bảng 7. Giá trị cản xạ HVL và TVL của mẫu thí nghiệm.

\begin{tabular}{|c|c|c|c|c|c|}
\hline \multirow{2}{*}{ STT } & \multirow{2}{*}{$\begin{array}{c}\text { Mẫu cấp } \\
\text { phối }\end{array}$} & \multicolumn{2}{|c|}{ Đỉnh $1173 \mathrm{KeV}$} & \multicolumn{2}{|c|}{ Đỉnh $1332 \mathrm{KeV}$} \\
\cline { 3 - 6 } & HVL (mm) & $\begin{array}{c}\text { TVL } \\
(\mathrm{mm})\end{array}$ & $\begin{array}{c}\text { HVL } \\
(\mathrm{mm})\end{array}$ & $\begin{array}{c}\text { TVL } \\
(\mathrm{mm})\end{array}$ \\
\hline 2 & CP1 & 48,2 & 160,0 & 49,3 & 163,7 \\
\hline 3 & CP2 & 38,7 & 128,4 & 42,2 & 140,9 \\
\hline 4 & CP4 & 48,4 & 160,9 & 48,2 & 160,1 \\
\hline
\end{tabular}

\section{Nhận xét}

Kết quả thí nghiệm độ sụt của hỗn hợp bê tông cho ta thấy độ sụt của cấp phối bê tông sử dụng quặng barite làm cốt liệu cao hơn so với cấp phối bê tông thông thường. Nguyên nhân là quặng barite có độ hút nước lớn hơn nhưng bề mặt cốt liệu tròn trơn hơn, lượng nước tạo hồ vữa xi măng ít hơn so với cốt liệu cát và đá dăm. Tác động của phụ gia hóa học giảm nước cũng đóng góp vào việc làm tăng độ sụt, nhưng đồng thời làm tăng khả năng thi công của hỗn hợp bê tông tươi. Độ sụt cao cũng làm tăng khả năng phân tầng tách lớp của bê tông sử dụng cốt liệu quặng barite. Với bê tông cốt liệu barite nên giữ đột sụt không quá $10 \mathrm{~cm}$ nhằm giảm khả năng phân tầng tách lớp trong quá trình thi công thực tế. Cấp phối tối ưu trong trường hợp này cần giảm khoảng 5 đến 10 \% lượng nước nhào trộn và tăng lượng phụ gia để dễ dàng thi công. 
Kết quả thí nghiệm khối lượng thể tích cho thấy khối lượng thể tích sụt giảm sau khi đổ và sau 28 ngày của bê tông cốt liệu barite là thấp hơn so với bê tông thông thường, điều này có thể là do lượng nước được giữ lại trong bê tông là lớn hơn, khả năng ngậm nước cao hơn. Khối lượng thể tích của bê tông cốt liệu barite khi thay thế cát (CP1), đá dăm (CP3), cát và đá dăm (CP2) so với bê tông thông thường (CP4) là cao hơn, tương ứng là $13,3 \%, 21,1 \%$ và $41,7 \%$, nguyên nhân là các cốt liệu cát barite và đá barite có khối lượng riêng lớn hơn $\left(4,33 \mathrm{~g} / \mathrm{cm}^{3}\right)$ so với khối lượng riêng của cát $\left(2,63 \mathrm{~g} / \mathrm{cm}^{3}\right.$ và đá dăm $\left(2,72 \mathrm{~g} / \mathrm{cm}^{3}\right)$. Để tối ưu hóa cấp phối bê tông cốt liệu barite ta có thể điều chỉnh lượng cát barite và đá barite với thành phần hạt phù hợp trong dải thành phần cốt liệu để xác định sơ bộ khối lượng thể tích thực tế ứng với giá trị cản xạ mong muốn.

Kết quả thí nghiệm cường độ nén cho thấy khi sử dụng cốt liệu quặng barite có sự sụt giảm cường độ, cụ thể cốt liệu barite khi thay thế cát (CP1), đá dăm (CP3), cát và đá dăm (CP2) so với bê tông thông thường (CP4) sụt giảm 11,6 \%, 5,1 \% và $21,9 \%$. Nguyên nhân: một là do tỷ lệ N/X tăng lên dẫn đến cường độ bê tông giảm; hai là do cốt liệu mịn dùng barite có mô đun đàn hồi thấp hơn, độ cứng của cốt liệu lớn sử dụng đá barite thấp hơn so với bê tông thông thường (điều này cần bổ sung thêm về mác đá thông qua chỉ tiêu cường độ nén dập xilanh mà đề tài chưa tiến hành). Để tối ưu hóa cấp phối bê tông sử dụng cốt liệu barite cần thiết phải tăng lượng xi măng trong cấp phối lên, giữ tỷ lệ $\mathrm{N} / \mathrm{X}$ thấp $(\mathrm{N} / \mathrm{X}=0.4-0.5[2,3,4])$ bù đắp phần cường độ sụt giảm.

Kết quả của thí nghiệm xác định giá trị cản xạ của bê tông cho ta thấy giá trị cản xạ HVL và TVL của bê tông cốt liệu cát barite khi thay thế cát (CP1), đá dăm (CP3), cát và đá dăm (CP2) so với bê tông thông thường (CP4) là cao hơn, tương ứng là $11,6 \%, 13,6 \%$, và $23,9 \%$. Điều này là do đóng góp của hàm lượng barite trong cấp phối tăng, tương ứng với khối lượng thể tích của bê tông tăng, nhưng mối quan hệ này không tăng tỷ lệ thuận với nhau.

Nghiên cứu cho ta thấy sử dụng quặng barite trong việc thiết kế chế tạo bê tông cản xạ làm tăng khả năng cản xạ của bê tông trên nguyên tắc làm cốt liệu thay thế cát và đá dăm, tăng khối lượng thể tích bê tông, bản chất là tăng mật độ bê tông nhằm nâng cao giá trị cản xạ (HVL, TVL) là đáp ứng yêu cầu.

\section{Kết luận}

Nhóm nghiên cứu đã tiến hành khảo sát đánh giá tính chất yêu cầu kỹ thuật của cốt liệu barite phù hợp với quy định, xác định được thành phần cấp phối bê tông cản xạ với yêu cầu kỹ thuật đáp ứng các chỉ tiêu cơ lý của bê tông thông thường và xác định khả năng cản xạ đối với tia gamma nguồn Cobalt 60 .

So với các nghiên cứu trên thế giới và Việt Nam, đề tài đã có những kết quả nghiên cứu về vật liệu bê tông có tính ứng dụng rõ rệt hơn: khẳng định cốt liệu barite tại địa phương có thể dùng thay thế cốt liệu chính cho vật liệu bê tông; chỉ dẫn kỹ thuật về vấn đề liên quan đến công tác thi công bê tông barite, về cách lựa chọn độ sụt và lượng phụ gia cần thiết đáp ứng tính linh động trong công tác trộn đổ bê tông nhằm tăng cường độ, độ đồng nhất vật liệu; đề xuất thay đổi thành phần hạt của cốt liệu trong việc thay đổi khối lượng thể tích nhằm mục đích tối ưu giá trị cản xạ.

Các kết quả nghiên cứu của đề tài về giá trị cản xạ của bê tông cốt liệu barite đã bổ sung phần thiếu hụt cho các nghiên cứu trong nước về vật liệu bê tông dùng để chống phóng xạ là công bố rõ giá trị cản xạ của vật liệu (HVL, TVL) tương ứng với cấp phối kèm theo, điều này là rất cần thiết đối với các công trình có hạng mục yêu cầu đặc tính cản xạ, là cơ sở để việc thiết kế xây dựng và đánh giá nghiệm thu an toàn bức xạ. Giá trị cản xạ và khối lượng thể tích trong nghiên cứu của đề tài và các nghiên cứu trên thế giới có mối liên hệ tỷ lệ thuận với nhau, tuy nhiên không trùng khớp kết quả do lựa chọn vật liệu barite của mỗi đề tài là khác nhau về hàm lượng barite trong cốt liệu.

Với kết quả nghiên cứu của đề tài về vật liệu bê tông barite, các công trình xây dựng có thể giảm khối lượng thi công đến $23,9 \% \mathrm{~m}^{3}$ bê tông hoặc giảm độ dày kết cấu xây dựng và che chắn bức xạ đến 23,9\%, điều đó đồng nghĩa với việc tiết kiệm chi phí xây dựng và tăng diện tích sử dụng của công trình.

Nghiên cứu còn nhiều vấn đề chưa đi sâu được: chưa tối ưu được lượng xi măng làm chất kết dính trong cấp phối; chưa thực hiện việc thí nghiệm và đánh giá ảnh hưởng của mác đá gốc đến cường độ nén của bê tông; vấn đề về sử dụng cốt liệu barite theo yêu cầu của tiêu chuẩn hiện hành đối với bê tông cản xạ (TCVN 9205:2012 với cát nghiền từ đá barite, TCVN 12208:2018 cốt liệu cho bê tông cản xạ) mới chỉ là nghiên cứu bước đầu. So sánh với các kết quả nghiên cứu trên thế giới, nhóm đề tài có kết luận tương đồng, nhưng chưa đi sâu nghiên cứu về ảnh hưởng của sự thay đổi hàm lượng barite trong các mẫu cấp phối dẫn đến sự thay đổi về khối lượng thể tích cũng như giá trị cản xạ (mối quan hệ giữa khối lượng thể tích và giá trị cản xạ của bê tông barite), để tối ưu hàm lượng barite trong cốt liệu.

Kiến nghị:

Dựa trên những kết quả nghiên cứu cũng như những vấn đề còn hạn chế của đề tài, nhóm nghiên cứu đề xuất có thể mở rộng nghiên cứu, kết hợp với các nhóm nghiên cứu về vật liệu bê tông, vật liệu mới, vật liệu tái tạo, theo một số hướng như sau:

- Nghiên cứu tối ưu hóa thành phần cốt liệu cho bê tông cản xạ sử dụng các cốt liệu tự nhiên hoặc nhân tạo trong các công trình xây dựng có yêu cầu tính cản xạ (các cốt liệu tự nhiên và nhân tạo theo TCVN 12208:2018)

- Nghiên cứu về bê tông cản xạ ứng dụng các công trình đặc thù sử dụng nguồn bức xạ năng lượng cao ( phòng chụp ảnh phóng xạ năng lượng cao, phòng máy gia tốc, lò phản ứng hạt nhân, ...)

\section{Tài liệu tham khảo}

[1]. M. S. Shetty, Concrete Technology: Theory and Practice, 1982.

[2]. Kilincarslan S, Akkurt I, Basyigit C, The effect of barite rate on the some physical and mechanical properties of concrete. Mater. Sci.Eng, A. 42: 8386, 2006. 
[3]. Izaz Ahmad, Khan Shahzada, Muhammad Imran Ahmad, Fayaz Khan, Yasir Irfan Badrashi, Sajjad Wali Khan, Noor Muhammad and Habib Ahmad, Densification of Concrete using Barite as Fine Aggregate and its Effect on Concrete Mechanical and Radiation Shielding Properties. Journal of Engineering Research 7(4):81-95, 2019.

[4]. K.A. Mahmoud, O.L. Tashlykov, A.F. El Wakil, I.E. El Aassy, Aggregates grain size and press rate dependence of the shielding parameters for some concretes. Progress in Nuclear Energy 118 103092, 2020.

[5]. I. Akkurt, H. Akyıldırım, B. Mavi, S. Kilincarslan \& C. Basyigit, Photon attenuation coefficients of concrete include barite in different rate. Annals of Nuclear Energy, 37(7): 910-914, 2010.

[6]. V. Fugaru, S. Bercea, C. Postolache, S. Manea, A. Moanta, I. Petre, M. Gheorghe, Gamma Ray Shielding Properties of Some Concrete Materials. APMAS, 2014.

[7]. IAEA Nuclear Security Series No. 5 Identification of Radioactive Sources and Devices

[8]. ASTM C637-14 Standard Specification for Aggregates for RadiationShielding Concrete

[9]. ASTM C638 - 14 Standard Descriptive Nomenclature of Constituents of Aggregates for Radiation-Shielding Concrete

[10]. Ahmed S. Ouda, Development of high-performance heavy density concrete using different aggregates for gamma-ray shielding, 2014.
[11]. Süleyman Özen; Cengiz Sengül; Teoman Ereno glu; Üner Çolak; Iskender Atilla Reyhancan; Mehmet Ali Tasdemir, Properties of Heavyweight Concrete for Structural and Radiation Shielding Purposes, 2015

[12]. QCVN 03:2012/BXD Quy chuẩn kỹ thuật quốc gia về nguyên tắc phân loại, phân cấp công trình dân dụng, công nghiệp và hạ tầng kỹ thuật đô thị

[13]. TCVN 12208:2018 Cốt liệu cho bê tông cản xạ

[14]. Vũ Mạnh Hùng; Phạm Quang Điện;Lê Quang Hiệp; Hà Sơn; Trần Ngọc Toàn; Lưu Văn Chức, Nghiên cứu chế tạo vật liệu cản xạ chống tia X, 1995

[15]. Trần Ngọc Tính, Nghiên cứu thiết kế cấp phối bê tông rất nặng sử dụng cốt liệu quặng barit Tuyên Quang, xi măng Bút Sơn PC40 dùng trong công trình cản xạ ở Việt Nam, 2004

[16]. Trần Lê Thắng, Nghiên cứu chế tạo bê tông đặc biệt nặng cản phóng xạ sử dụng trong xây dựng nhà máy điện hạt nhân ở Việt Nam, 2004.

[17]. https://vatlieuxaydung.org.vn/vlxd-ket-cau/be-tong/be-tong-can-xa-trenco-so-vat-lieu-trong-nuoc-4308.htm

[18]. http://www.moc.gov.vn/c/document_library/get_file?p_1_id=26808\&fold erId $=48304 \&$ name $=29019$

[19]. "Chỉ dẫn kỹ thuật chọn thành phần bê tông các loại“ theo quyết định số 778/1998/QĐ-BXD

[20]. TCVN 9205:2018 - Cát nghiền cho bê tông và vữa. 